\title{
Microstructure and mechanical properties of an ODS RAF steel fabricated by hot extrusion or hot isostatic pressing
}

\author{
P. Unifantowicz ${ }^{a, *}$, Z. Oksiuta ${ }^{\text {b }}$, P. Olier ${ }^{c}$, Y. de Carlan ${ }^{c}$, N. Baluc ${ }^{a}$ \\ a Ecole Polytechnique Fédérale de Lausanne (EPFL), Centre de Recherches en Physique des Plasmas, Association Euratom-Confédération Suisse, 5232 Villigen PSI, Switzerland \\ ${ }^{\mathrm{b}}$ Politechnika Bialostocka, Wydzial Mechaniczny, ul. Wiejska 45, 15-351 Bialystok, Poland \\ c CEA/DEN/DMN/SRMA, CEA Saclay, 91191 Gif-sur-Yvette Cedex, France
}

\section{A R T I C L E I N F O}

Article history:

Available online 12 February 2011

\section{Keywords:}

Fusion materials

ODS steels

Hot isostatic pressing

Hot extrusion

$\mathrm{YTiO}_{3}$

\begin{abstract}
A B S T R A C T
Ingots of an oxide dispersion strengthened reduced activation ferritic steel with the $\mathrm{Fe}-14 \mathrm{Cr}-2 \mathrm{~W}-0.3 \mathrm{Ti}-0.3 \mathrm{Y}_{2} \mathrm{O}_{3}$ chemical composition (in wt.\%) were synthesized by mechanical alloying of elemental powders with $0.3 \mathrm{wt} . \% \mathrm{Y}_{2} \mathrm{O}_{3}$ particles in a planetary ball mill, in a hydrogen atmosphere, and compacted by either hot extrusion or hot isostatic pressing. The microstructures of the obtained materials were characterized by means of light microscopy, transmission electron microscopy and chemical analyses. The mechanical properties were evaluated by means of Vickers microhardness measurements and tensile tests. It was found that the microstructure of both materials is composed of ferritic grains having a submicron size and containing nanometric Y-Ti-O oxide particles with a mean size of about $10 \mathrm{~nm}$, uniformly distributed in the matrix. The oxide particles in the hot extruded steel were identified as $\mathrm{YTiO}_{3}$ phase. In larger $(>10 \mathrm{~nm})$ oxide particles $\mathrm{Cr}$ was found next to Ti, $\mathrm{Y}$ and $\mathrm{O}$. The steel produced by hot extrusion exhibits much higher tensile strength and hardness at low to moderate temperatures, as compared to the steel fabricated by hot isostatic pressing, which was mainly attributed to smaller pores but also to more severe work hardening in the case of the hot extruded steel.
\end{abstract}

(c) 2011 Elsevier B.V. All rights reserved.

\section{Introduction}

Numerous international research programs aiming at the development of reduced activation steels for fusion reactor applications point at nano-structured, ferritic, oxide dispersion strengthened (ODS) alloys as promising structural materials with respect to their improved radiation resistance as well as high-temperature strength and creep resistance in comparison with the un-reinforced ferritic or ferritic/martensitic steels [1-4].

Reduced activation ODS ferritic steels contain the following elements in an iron matrix: chromium $(\sim 9-14 \%)$ which provides stability of the ferritic structure, causes solid solution hardening and corrosion resistance, tungsten which contributes to solid solution hardening and improves the thermal stability of the alloy, and small amounts $(\sim 0.3 \%)$ of titanium and yttrium forming nanooxides which improve the steel resistance to creep, fatigue and radiation damage.

The production of nano-structured ODS ferritic steels usually involves powder metallurgical methods including mechanical alloying and subsequent powder compaction using either hot extrusion (HE) [1] or hot isostatic pressing (HIP) [5,6]. HIP usually

\footnotetext{
* Corresponding author.

E-mail address: paulina.unifantowicz@psi.ch (P. Unifantowicz).
}

yields a more isotropic microstructure but a lower ductility and fracture toughness as compared to the materials produced by HE [7].

In this work, two reduced activation ODS ferritic steels fabricated by mechanical alloying followed by either HE or HIP were investigated in order to assess the influence of each consolidation method on the microstructure and mechanical properties of the obtained ingots. For the first time, the size and morphology of microstructure elements such as pores, grains and oxide nanoparticles along with mechanical properties were compared for $14 \mathrm{Cr}$ ODS ferritic steels after HE and HIP.

\section{Experimental}

Elemental powders of $\mathrm{Fe}$ (99.95\%), 14\% Cr (99.5\%), 2\% W, 0.3\% Ti and $0.3 \% \mathrm{Y}_{2} \mathrm{O}_{3}$ (in wt.\%) were milled in a planetary ball mill, in a hydrogen atmosphere, using the conditions reported in [8]. A first batch $(500 \mathrm{~g})$ of as-milled powder was encapsulated in a soft steel can, degassed at $400^{\circ} \mathrm{C}$ for $2 \mathrm{~h}$ and, after a preheating for $1 \mathrm{~h}$ at $1100^{\circ} \mathrm{C}$, hot extruded through a round channel $(\varnothing 20 \mathrm{~mm})$ using a $500 \mathrm{t}$ press. A second batch $(200 \mathrm{~g})$ of the same powder was, after canning and degassing, subjected to HIP by applying an Ar pressure of $200 \mathrm{MPa}$ for $4 \mathrm{~h}$ at $1150^{\circ} \mathrm{C}$. Subsequently, the consolidated ingots were subjected to a heat treatment in vacuum for $1 \mathrm{~h}$ at $850^{\circ} \mathrm{C}$ followed by furnace cooling. 
The microstructures of the compacted steels were investigated using a transmission electron microscope (TEM), JEOL-2010 with an energy dispersive X-ray spectroscopy (EDS) detector for chemical analyses and a light microscope (Zeiss) for metallographic analyses. The TEM lamellae were prepared using a TENUPOL (Struers) electropolishing unit. The microhardness of the steels was measured at room temperature using a Vickers tester. Tensile tests were carried out on flat samples $(18 \mathrm{~mm} \times 3 \mathrm{~mm} \times 0.5 \mathrm{~mm})$ using a Zwick testing machine equipped with a furnace enabling heating the samples up to $1000^{\circ} \mathrm{C}$ in an Ar flow. Tensile tests were performed at various temperatures between room temperature and $750^{\circ} \mathrm{C}$.

\section{Results and discussion}

\subsection{Microstructure characterization}

\subsubsection{Light microscopy}

Light microscopy enabled a comparison of general microstructures of the two $14 \mathrm{Cr}-2 \mathrm{~W}-0.3 \mathrm{Ti}-0.3 \mathrm{Y}_{2} \mathrm{O}_{3}$ ODS steel ingots produced by either HE or HIP. Fig. 1(a and b) shows as-polished surfaces of the two steels. Micropores with a size in the range of $0.04-1 \mu \mathrm{m}$ are visible, as confirmed by the images at different polarization angles shown in Fig. 1(c). The micropores which remained after consolidation of mechanically alloyed powders occupy a similar area fraction in both steels but are on average twice larger in the case of the HIP steel $(0.42 \mu \mathrm{m})$, as compared to the HE steel $(0.26 \mu \mathrm{m})$, as determined from image analysis. Although the porosity deteriorates materials mechanical properties and could be reduced by applying additional thermo-mechanical treatments, for instance, this issue was not addressed in the present study.

\subsubsection{Transmission electron microscopy}

TEM observations of the two investigated materials showed that they are composed of submicron equiaxed grains of ferritic iron, as can be seen in Fig. 2. The bcc structure of $\alpha$-Fe was confirmed by selected area electron diffraction (SAED) patterns (see inserts in Fig. 2). The mean grain size was measured from TEM images, Fig. 2(a-c) was found equal to $39 \mathrm{~nm}$ and $78 \mathrm{~nm}$ in the transverse

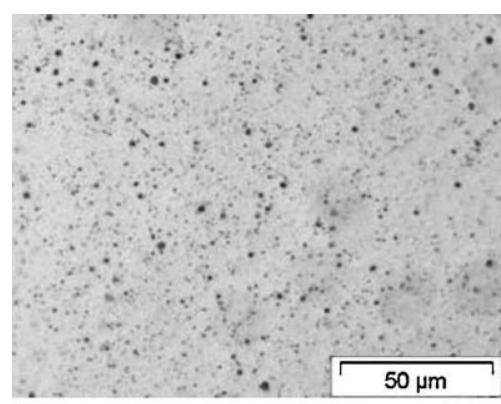

(a)

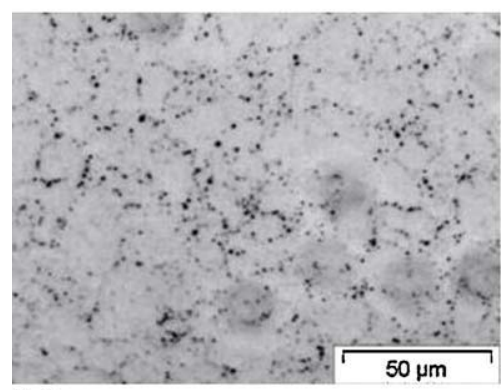

(b)

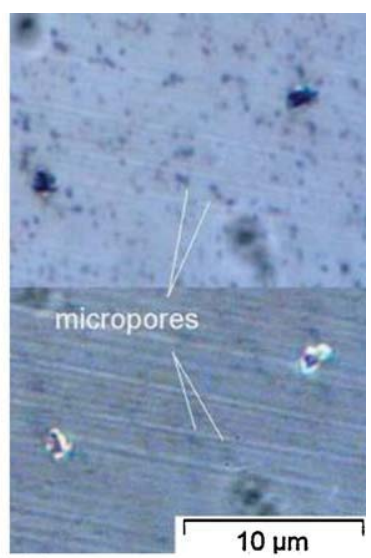

(c)
Fig. 1. Unfiltered LM images of (a) HE and (b) HIP steels, and (c) LM images of the HE steel at different polarization angles.

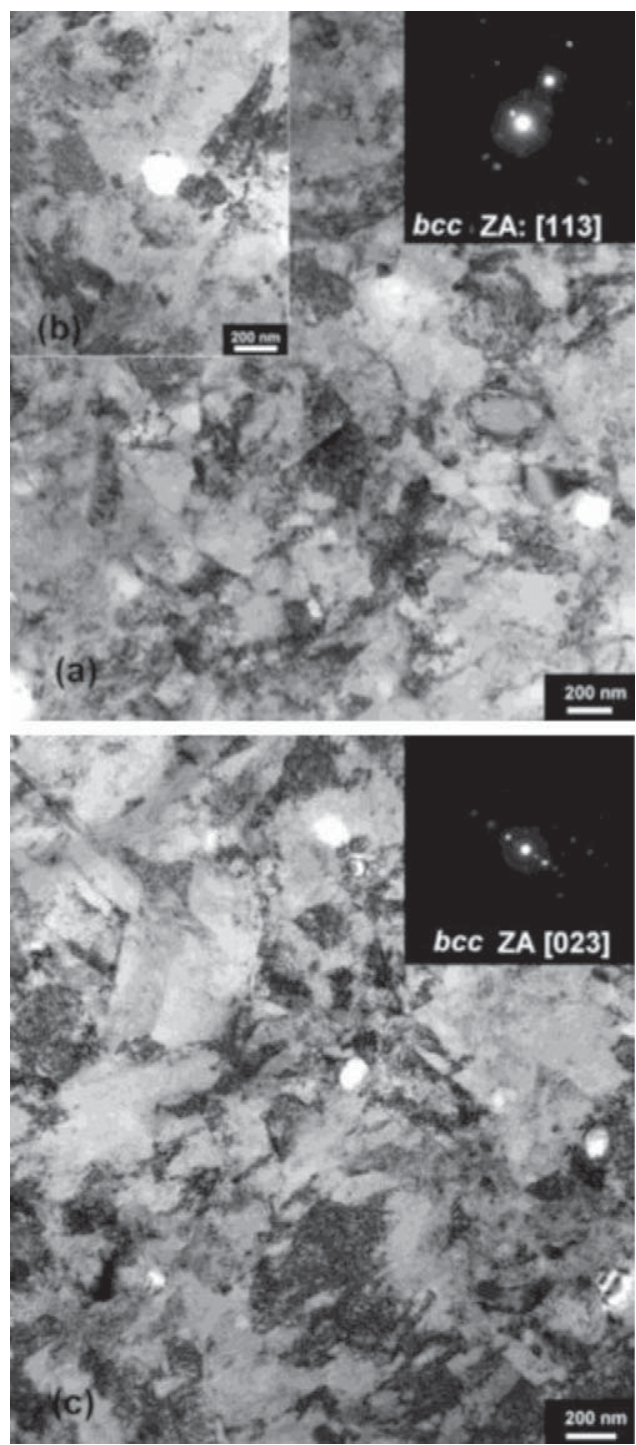

Fig. 2. TEM images of the HE steel in (a) the transverse, (b) the longitudinal direction (extrusion), and (c) of the HIP steel. SAED patterns refer to [113] and [023] zone axes of $\alpha$-Fe grains in HE and HIP steel, respectively.

and longitudinal (extrusion) direction, respectively, in the case of the HE steel. In the case of the HIP steel, the mean grain diameter was found equal to about $80 \mathrm{~nm}$. However, the shape of the grains was found similar in both investigated materials. The circularity factor is on average between 0.50 for the HIP steel and 0.54-0.58 for the HE steel, confirming the presence of fairly equiaxed grains structure in the latter, which is atypical for HE steels [7].

TEM dark-filed images at higher magnifications in Fig. 3(a and b) showed the presence of nanoparticles having a size in the range $\sim 1-100 \mathrm{~nm}$ in both investigated steels. The nanoparticles have a mean diameter of about $8 \mathrm{~nm}$ in the HE steel and $4 \mathrm{~nm}$ in the HIP steel. The number density of nanoparticles was estimated using thickness fringes in dark field TEM images, High number densities of $17.4 \times 10^{23} \mathrm{~m}^{-3}$ and $9.3 \times 10^{23} \mathrm{~m}^{-3}$ were measured in the case of the HE steel and the HIP steel, respectively.

High resolution TEM images in Fig. 4 showed that the nanoparticles have diameter of about $10 \mathrm{~nm}$ and spherical or faceted shape. Assuming dissolution of yttria in iron upon mechanical alloying, the HE or HIP process temperature should enable diffusion of yttrium in iron during the consolidation process, even though the compaction temperature was far below the yttria melting point. Thus, the size 


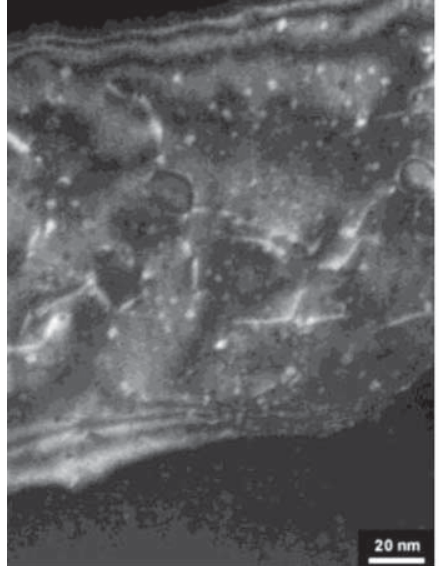

(a)

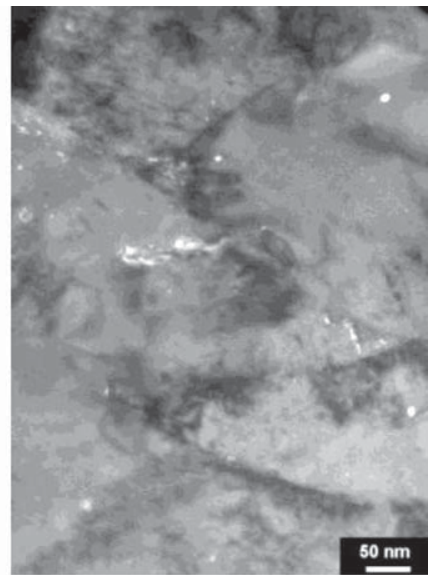

(b)

Fig. 3. Dark field TEM images of oxide particles in the ODS ferritic steel after (a) HE and (b) HIP.

and shape of nanoparticles can change upon powder consolidation via surface diffusion processes.

Distances between the interatomic layers estimated by using Fourier transform were of 0.76 and $1.1 \pm 0.05 \mathrm{~nm}$ for the oxide particles in both investigated materials. This distances correspond to

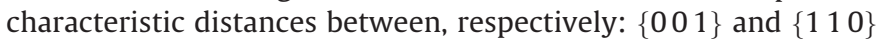
planes in $\mathrm{YTiO}_{3}$ phase having an orthorhombic structure (Pnma space group) [9]. However, in order to confirm the $\mathrm{Y}_{x} \mathrm{Ti}_{y} \mathrm{O}_{z}$ particles composition and structure, a more detailed analysis is needed.

\subsubsection{Energy dispersive $X$-ray spectroscopy}

EDS maps shown in Fig. 5( $a$ and b) were obtained using the STEM unit of the TEM, with a focus on identifying the chemical elements present in the nanoparticles, in the case of both investigated steels. Titanium, yttrium and also chromium were found next to oxygen in particles having a size in the range $30-50 \mathrm{~nm}$ in the HE steel and in slightly larger particles, with a size in the range $50-100 \mathrm{~nm}$, in the HIP steel, revealing the formation of complex oxides in both materials. Tungsten was found uniformly distributed in the matrix and not related to tungsten carbide formation.

Regarding the small weight percent of yttrium in the ODS steels, its presence in nano-sized oxides smaller than $10 \mathrm{~nm}$ was not possible to verify on the basis of EDS maps.

\subsection{Tensile and microhardness tests}

The two investigated materials exhibit different ultimate tensile strength (UTS) and uniform elongation $\left(\varepsilon_{\mathrm{u}}\right)$ behaviors versus test temperature. The results plotted in Fig. 6 show that the HE steel has

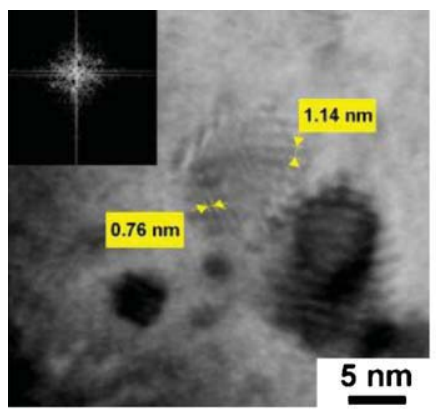

(a)

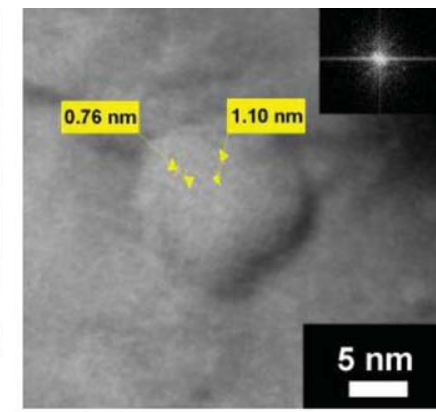

(b)
Fig. 4. Bright field TEM images of nano-particles in (a) HE and (b) HIP steel with indicated interatomic layer spacing found from Fourier transform.
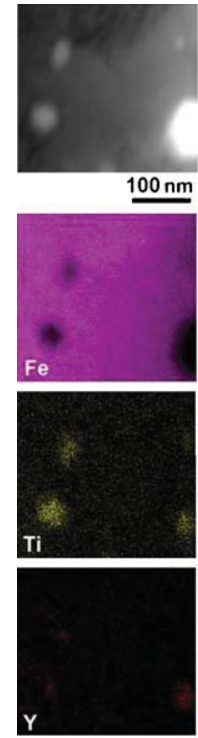

(a)
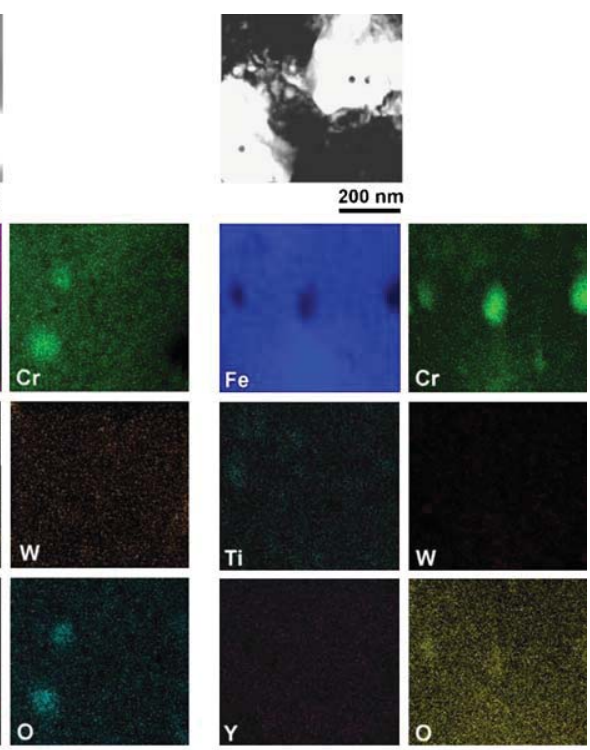

(b)
Fig. 5. STEM images and EDS maps for the ODS ferritic steels produced by (a) HE and (b) HIP.

a much higher UTS at room temperature ( $2500 \mathrm{MPa}$ ) than the HIP steel ( $\sim 900 \mathrm{MPa})$. The UTS value of both materials decreases with increasing test temperature. At $750^{\circ} \mathrm{C}$ both steels exhibit a similar UTS of about $250 \mathrm{MPa}$. The $\varepsilon_{\mathrm{u}}$ of the HE steel increases continuously from about $3 \%$ at room temperature to about $7.8 \%$ at $750{ }^{\circ} \mathrm{C}$. Whereas the $\varepsilon_{\mathrm{u}}$ of the HIP steel increases from about 6\% at room temperature up to about $10.5 \%$ at $300^{\circ} \mathrm{C}$ and then deceases down to about $4.2 \%$ at $750{ }^{\circ} \mathrm{C}$. Note that presence of $\mathrm{Y}-\mathrm{Ti}-\mathrm{O}$ particles does not prevent an important loss of strength to take place between 500 and $600^{\circ} \mathrm{C}$, whatever the strength value at room temperature.

Results of hardness tests showed that the HE steel exhibits a significantly higher $\mathrm{HV}_{0.1}$ value of $936 \pm 22$ at room temperature than the HIP steel $\left(\mathrm{HV}_{0.1}=414 \pm 9\right)$, in agreement with results of tensile tests.

The very high tensile strength and microhardness of the HE steel can be related to the mechanism of powder compaction in which very high pressures are exerted on the powder particles, yielding the formation of a high density of structural defects and strong work hardening. In addition, the higher density of nanoparticles evidenced in the HE steel might also contribute to the much higher strength values measured for the HE steel at low to moderate tem-

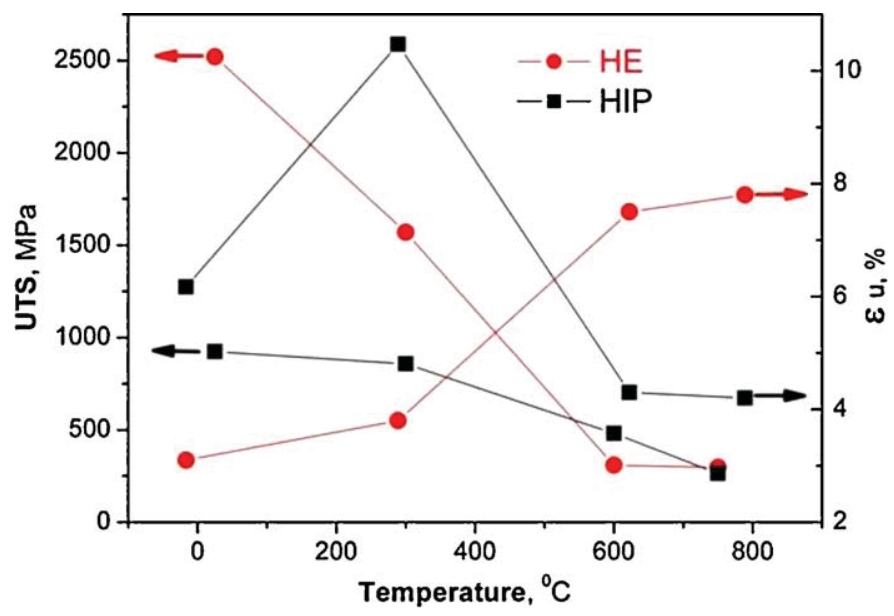

Fig. 6. UTS and $\varepsilon_{\mathrm{u}}$ versus test temperature for the ODS ferritic steels after HE or HIP. 
peratures. The strong decrease in UTS, associated with an increase in $\varepsilon_{\mathrm{u}}$, observed for the HE steel might be attributed to temperature controlled recovery mechanisms which facilitate plastic flow.

\section{Conclusions}

The two investigated $14 \mathrm{Cr}$ ODS ferritic steels, manufactured by mechanical alloying followed by either HE or HIP, display significant differences in their microstructures and mechanical properties.

Both materials contain fairly equiaxed grains having a mean diameter in the range of $40-80 \mathrm{~nm}$ and a high number density of nano-sized oxide particles. The grains elongation is not substantially higher in the HE steel. In both materials, the larger oxides appear enriched with $\mathrm{Cr}$, Ti and $\mathrm{Y}$, as revealed by EDS analyses. High-resolution TEM showed the presence of about $10 \mathrm{~nm} \mathrm{YTiO}_{3}$ oxides in the HE steel. However, the formation of other types of $\mathrm{Y}-\mathrm{Ti}-\mathrm{O}$ oxides is not excluded.

The HE steel exhibits a higher tensile strength at low to moderate temperatures than the HIP steel, in relation with the HE process, yielding a deformed microstructure and important work hardening effects, and also the presence of a higher number density of nanosized oxides. At higher temperatures, although both steels have a similar tensile strength, the HE steel shows higher uniform elongation, which could indicate a more pronounced tendency of the microstructure to recovery mechanisms, enhancing plastic flow.

\section{Acknowledgments}

The Paul Scherrer Institute is acknowledged for the overall use of its facilities. This work, supported by the European Communities under the contract of Association between EURATOM/Confédération Suisse, was carried out within the framework of the European Fusion Development Agreement. The views and opinions expressed herein do not necessarily reflect those of the European Commission. This work was also performed within the framework of the Integrated European Project "ExtreMat" (contract NMP-CT-2004-500253) with financial support by the European Community. It only reflects the view of the authors and the European Community is not liable for any use of the information contained therein.

\section{References}

[1] R. McClintock, et al., Journal of Nuclear Materials 386-388 (2009) 307-311.

[2] S.M. Ukai, M. Fujiwara, Journal of Nuclear Materials 307-311 (2002) 749-757.

[3] R. Lindau, et al., Fusion Engineering Design 75-79 (2005) 989-996.

[4] D.T. Hoelzer, et al., Journal of Nuclear Materials 367-370 (2007) 166-172.

[5] M. Klimienkov, et al., Journal of Nuclear Materials 386-388 (2009) 553-556.

[6] V. de Castro, et al., Journal of Nuclear Materials 386-388 (2009) 449-452.

[7] P. Olier, et al., Journal of Nuclear Materials 386-388 (2009) 561-563.

[8] Z. Oksiuta, N. Baluc, Nuclear Fusion 49 (2009), 055003 pp 9.

[9] J.R. Hester, et al., Acta Crystallographica B 53 (1997) 739-744. 